\title{
Converses amb Xavier Melgarejo
}

\author{
Entrevistat per Isabel Viscarro
}

Universitat Rovira i Virgili

Xavier Melgarejo Draper és doctor en pedagogia, llicenciat en Psicologia i postgraduat en Direcció de Centres Escolars. Té una llarga experiència en làmbit escolar, concretament al col-legi Claret de Barcelona, on ha exercit diferents funcions: professor de secundària, cap del departament d'Orientació Psicopedagògica, director i, actualment, coordinador pedagògic.

És president de la Comissió d'Ordenació del Consell Escolar de Catalunya, assessor del Consell Superior d'Avaluació de Catalunya, president de la Comissió d'Educació de la SEBAP de Barcelona, assessor del Departament d'Educació de la Generalitat sobre el Sistema Educatiu Finlandès, membre de la Comissió Assessora de la Facultat d'Educació de la Universitat de Barcelona, collaborador de l'Institut Iberoamericà de Finlàndia i representant del Ministeri d'Educació Finlandès als països Iberoamericans. També és membre del jurat dels Premis de Catalunya d'Educació i membre del grup que treballa en el Programa per la Millora del Magisteri (MIF).

En làmbit universitari, ha impartit docència en el curs de postgrau d'Orientació i Tutoria i en el de Direcció de Centres Educatius de la Universitat Ramon Llull.

És autor de nombroses publicacions sobre diversos temes d'educació i del sistema educatiu a Finlàndia. Recentment, ha publicat el llibre Gracias, Finlandia.
Ha estat convidat a donar conferències, ponències, seminaris $i$ jornades en diferents països i contextos, com pot ser el Senat, el Ministeri d'Educació i Ciència, el Congrés dels Diputats o diferents universitats tant de Catalunya com de la resta de l'Estat. També ha participat en programes de diferents mitjans de comunicació, en premsa, ràdio i TV.

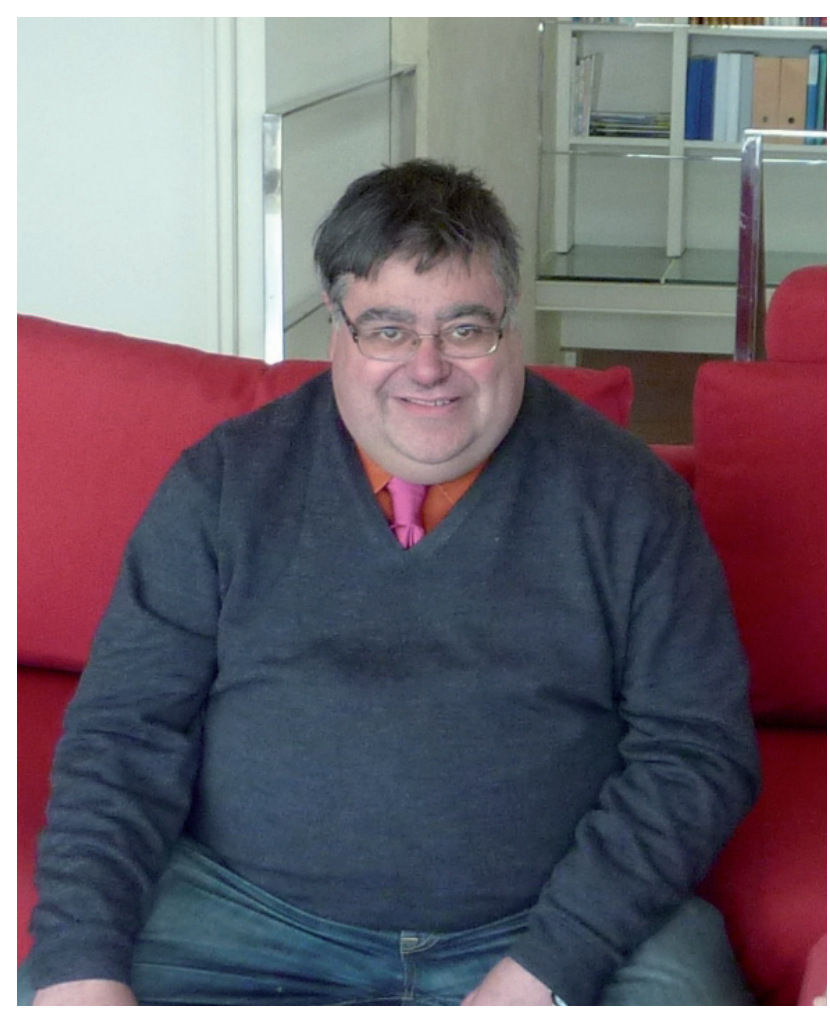


Xavier, és un plaer poder-te entrevistar, alhora que agraeixo la teva disponibilitat tenint en compte els compromisos que tens darrerament.

Des que et vaig descobrir al programa Singulars, he anat escoltant les entrevistes que has concedit a diferents mitjans de comunicació, i també l'esplèndida ponència amb què ens vas obsequiar en la inauguració al màster en Pedagogia Sistèmica a la Facultat de Ciències de l'Educació de Tarragona. La conferència, que va ser interessantíssima, es va magnificar amb la lliçó de vida que ens vas donar arran de com vius la teva malaltia. Podeu veure: Xavier Melgarejo i Josep Maria Cervera (2012). Davant l'adversitat: amor i llibertat. Barcelona: Editorial Claret.

Xavier, has estudiat a fons el sistema educatiu de Finlàndia, un model educatiu que es posa com a mostra pels bons resultats que obtenen els seus estudiants. Com a expert, ens podries comentar quines són les claus del seu èxit?

En primer lloc, gràcies per donar-me l'oportunitat de dirigir-me a tots els vostres lectors i lectores.

En relació amb quina és la finalitat del sistema, doncs són les persones. La idea principal dels finlandesos és construir persones, persones integrals, fent-ho d'una manera que no sigui angoixant, sense pressions excessives, crear persones que després estiguin compromeses socialment, amb un sentit ètic. En altres països que he visitat hi ha una gran competitivitat que fa que es vagin trepitjant els uns als altres, o amb la qual, depenent dels resultats que s'obtenen, es pot anar a un lloc o a un altre. A Finlàndia la idea és que hi ha d'haver una gran equitat i que una persona, tingui la situació inicial que tingui, pugui accedir a la mateixa igualtat d'oportunitats que una altra.

En el fons, com passa en els països asiàtics, on existeix una cultura confuciana molt gran, a la cultura finlandesa hi ha una base cristiana d'igualtat i equitat que està empenyent des del fons. Això vull dir-ho perquè penso que és important que la gent ho sàpiga. A Finlàndia, els pastors luterans, en el fons, són els més grans defensors de l'estat del benestar i de l'escola d'aquest tipus. Per què? Doncs perquè tot aquest pensament no ha sorgit de l'aire, té els orígens aquí.

Aquesta equitat i qualitat alhora és el que em va agradar de Finlàndia. Fa molts anys, quan la vaig descobrir, ja hi havia resultats molt bons del Japó, tan bons o més que els de Finlàndia, però per a què eduquem? Aquesta és la gran pregunta, per a fer què? Curses de cavalls, com sembla que hi ha països que van en aquesta direcció, o per crear ciutadans amb ètica, responsables, moralment compromesos, amb una sensibilitat humana, i a més, competents, no competitius? És clar, a mi magrada aquest model. Crec que el cas de Finlàndia és interessant perquè ens dóna una resposta des d'una perspectiva humanista en la qual la persona és el centre, on hi ha una concepció dels drets humans important i amb una tradició lligada a la nostra cultura europea i cristiana que a mi magrada.

Per aquest motiu crec que val la pena mirar cap a Finlàndia, no hem de copiar el model, però podem tenir com a referència les seves grans concepcions i construir una societat basada en el coneixement. Tanmateix, això no es pot fer sense una societat que sigui equitativa i que estimi tothom amb equitat. Aquesta concepció que al final hi ha una estimació per a tothom em sembla una diferència interessant $i$, a mi, magradaria que també hi fos a Catalunya, a Espanya i al món. Crec que és una de les coses maques que des d'Europa es pot enviar com a missatge al món.

A Finlàndia es considera el sistema educatiu com un engranatge perfectament encaixat del qual formen part els tres subsistemes - famílies, alumnes i mestres-, cadascun amb les seves funcions però treballant conjuntament per assolir l'èxit. En el nostre sistema educatiu, quin encaix hi tenen aquests tres elements?

Per començar, hi ha una part d'aquests subsistemes que no és reconeguda jurídicament. El fet que la família estigui tan apartada de tots els subsistemes, tal com es concep en les lleis i en els escrits oficials, la deixa fora de tota responsabilitat, i això no crec que estigui fet sense intenció, crec que és una qüestió d'apropiació per part de l'Estat del tema educatiu i per aquesta raó no pot funcionar.

Si qualsevol ministre creu que tocant una llei es canviarà el que passa en una escola, s'equivoca, perquè el que passa en una escola passa perquè pedalegen els mestres, els pares i els alumnes que 
estan en aquella escola, i si ells no ho fan, no ho farà ningú. És clar, si la família en queda a fora, com és el que està passant en aquest moment, el sistema se'n ressent.

Fa un moment m'ha trucat el president de l'AMPA d'una escola d'Alzira per demanar-me fer una xerrada que els ajudés a integrar les famílies a l'escola, $i$ això és el que en el fons voldria molta gent, però la nostra legislació no ho reconeix. I ara, amb la nova llei d'educació, el paper de la família a les escoles quedarà molt més reduït, els consells escolars no tindran l'autoritat que tenien abans i crec que es notarà. Perquè les famílies s'hi puguin implicar primer se n'ha de reconèixer l'existència.

Les famílies fan una tasca que considero imprescindible. A Finlàndia, quan li preguntes a un nen o una nena qui és el responsable del seu aprenentatge, el primer que et respon és “jo", perquè si no ho fas tu, no ho farà ningú. En aquesta escala és la família la que inculca que primer sóc "jo" i després és l’escola; aquí els mestres lluiten com si fossin els primers, és a dir, tothom està empenyent per reconduir el seu rol. Aquí quan preguntes als infants qui és el responsable de la seva vida, n'hi ha que no entenen la pregunta $i$ fins i tot et pregunten que què vol dir ser responsable, després et poden contestar que el seu pare o mare. Al final preguntes: "I tu?" Llavors et responen que sí, que ells també.

Quan l'OCDE en les proves PISA preguntava qui era el responsable de l'educació a diferents països, a Finlàndia la majoria responien que primer era la família i després eren els mestres; aquí tan sols un $15 \%$ donava la mateixa resposta. Això què vol dir? Doncs que aquí hi ha moltes famílies que no se’n responsabilitzen. Jo crec que no és que les famílies passin (que n'hi ha que sí que ho fan), sinó que hi ha hagut una política educativa que ho ha facilitat. Tot i així, la gent va a l'escola $a m b$ ànims de participar perquè en el fons hi ha una gran voluntat, però s'hi troben molts obstacles.

Si la participació funciona, les coses surten, vull dir que al final la comunitat és la que educa; no és ni el ministre, ni el govern, ni les lleis: és la comunitat. Per tant, hem de buscar lleis, expressions i possibilitats que donin autonomia a la comunitat perquè pugui resoldre els problemes de la seva escola, ja que els problemes d'Alzira no són els mateixos que els de Barcelona o de Tarragona, fins i tot a Tarragona hi haurà barris amb unes problemàtiques diferents a d'altres. L'escola ha de donar resposta als seus problemes, i afrontar-los de manera diferent en funció del context, però si no tenen aquesta possibilitat, si no es pot treballar de forma conjunta amb aquella part de la comunitat que són les famílies, si no s'obre l’escola al barri, a la ciutat, al país i no hi ha una mirada de l'escola cap a fora alhora que una permeabilitat de fora cap a dintre, obrint-se en totes dues direccions, l'escola queda com una bombolla ailllada de la vida i així no pot funcionar.

Llavors aquest engranatge sistèmic no funciona, es bloqueja, que al final és el que passa. Penso que el sistema no és exclusivament l'escola, sinó que és més ampli $i$, per la teoria de sistemes, els elements que formen part d'un sistema no poden estar fora, per lògica han d'estar a dintre. El que passa és que les lleis no ho volen acceptar; tampoc ideològicament és fàcil, perquè acceptar-ho vol dir compartir aquest poder amb altres estructures i planificar polítiques diferents. Per exemple, la família a Finlàndia una de les coses més importants que té és la compatibilitat entre la vida laboral i la familiar, i això es va pactar globalment. Per què és important? Doncs perquè per a tu els teus fills són el més important i partint d'això es pregunten: com es pot fer per complir amb la teva vida laboral i a la vegada poder ser a casa a les cinc de la tarda?

Aquí hi ha molta gent que a les cinc no pot estar disponible per als fills i moltes persones se'n senten culpables, perquè voldrien però no poden. I, a més, encara els diem que haurien d'estar més amb els seus fills, però no saben com fer-ho.

$\mathrm{Al}$ meu parer, el sistema no està ben enfocat perquè ha d'incloure les tres estructures: la familiar, l'escolar i la sociocultural conformada per les diferents institucions o xarxes que ens ajuden, com ara l'Església, que està fent una feina educativa molt important, la xarxa de biblioteques, els mitjans de comunicació... Per tant, si en qualsevol dels àmbits podem crear sinergies positives, segons la llei de sistemes es produiran canvis positius que afectaran tot el sistema i ho podem fer 
a qualsevol lloc: des d'una biblioteca, una escola, una església, una ràdio o una universitat, i això és el que és bonic.

Hem de buscar la manera de potenciar les iniciatives perquè les famílies que vulguin participar puguin fer-ho, com és el cas l'AMPA d'Alzira i tants d'altres. Aquí a l'escola, per posar un exemple, els divendres fan un contacontes amb la participació de les famílies: hi vénen avis, pares, tiets, gent que coneixen... És molt bonic; a més, veus que ve algun immigrant que porta l'avi de molt lluny a explicar un conte del seu país. Hi ha vuitanta o noranta nens d'infantil, i això permet crear aquesta xarxa de què hem parlat, aquesta comunitat, donar un missatge positiu cap a la importància de la lectura, cap a la biblioteca, que el professorat i l'alumnat compartim amb els pares i mares aquesta creença. Si no hi ha aquest tipus de tasques, l'escola què és? Que de nou a deu tinc classe de mates i de deu a onze tinc pati? Això? Això no pot funcionar.

Jo sóc una persona amb molta esperança i més després de veure com la gent reacciona da- vant de situacions diverses, perquè hi ha molta gent que des del seu petit àmbit intenta millorar. Fa uns dies vaig estar a Extremadura i una de les persones que em va impactar va ser el director de la Biblioteca Nacional de Mérida; va voler que la televisió local em gravés parlant a la biblioteca perquè la gent fos conscient de la importància de la lectura. Em va comentar que quan va anar a Finlàndia li va cridar l'atenció la quantitat de llibres que la gent s'emportava i ell vol fer-ne difusió per potenciar la lectura i que la gent s'hi interessi i vingui a la biblioteca.

Les persones han de sentir que formen part d'aquest engranatge, s'han de sentir volgudes i creure que són necessàries en aquesta tasca de lluita. Vull fer un reconeixement als vostres lectors, que amb entusiasme i molta voluntat estan fent una gran tasca per tirar l'escola endavant; en primer lloc, tota la meva estimació cap a ells, la meva alegria de formar part d'aquest col-lectiu i també la meva convicció que, malgrat que a vegades tinc la sensació que no poden fer més, estan provocant que a mitjà i llarg termini es produei-

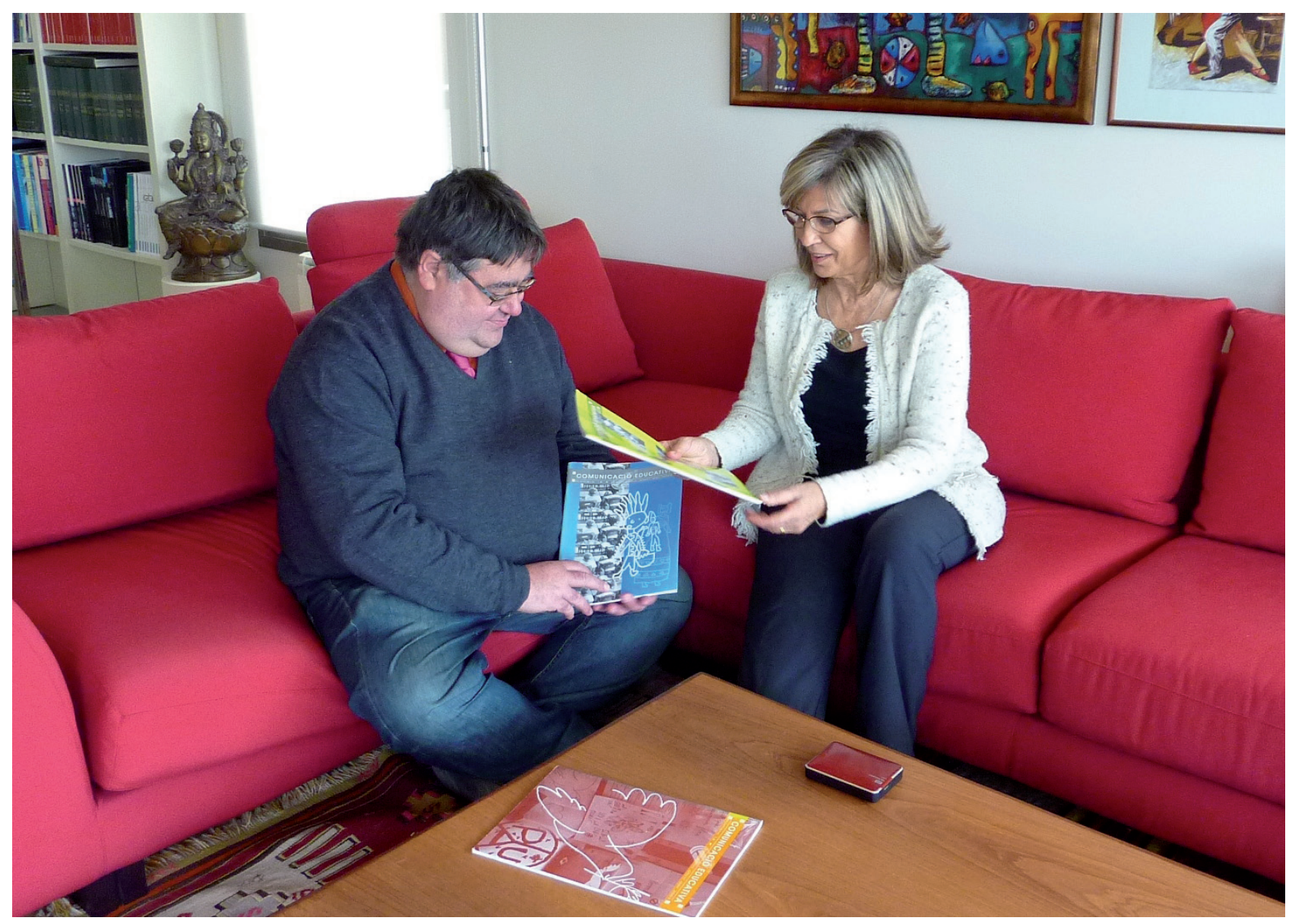


xin els canvis que veurem, el que passa és que no poden fer-ho sols, ho hem de fer tots junts.

És clar que una persona sola o un col-lectiu petit no pot fer gran cosa, però s'estan veient canvis; de fet, està sorgint allò que comentaves, Xavier, sobre les comunitats d'aprenentatge. El que passa és que, de moment, tot i que hi ha col-lectius que estan treballant molt, les evidències encara són minses, s'haurien d'anar estenent més $i$ les xarxes socials d'interessos reals poden ajudar-hi molt, perquè les noves tecnologies de la comunicació faciliten la circulació de la informació de manera molt ràpida.

Jo penso que estem en un moment en què aquestes xarxes que s'estan creant, si s'utilitzen de manera adequada, seran una eina de construcció social potent. Aquest matí m'ha escrit un professor de la Universitat de Jaén, que no coneixia, i que a partir del llibre ha contactat amb mi per fer alguna col-laboració. Això fa vint anys era impensable i ara aquestes eines ens donen la possibilitat de poder-nos ajudar molt a escala de comunitat.

Vosaltres, amb la revista Comunicació Educativa que avui m'heu presentat, esteu creant una xarxa amb la qual doneu saba de vida i la feu circular per la comunitat de les comarques de Tarragona, i és molt bonic donar resposta a les comunitats que hi ha. Aquesta xarxa s'anirà estenent progressivament i posant-se en contacte amb altres xarxes que casualment estan buscant $i$ fent el mateix, i es pot anar creant una gran xarxa.

I així s'està generant una xarxa de coneixement molt enriquidora que sorigina a la base sense cap ajuda dels governants, amb la qual cosa és enormement lliure i prendrà la direcció que ella vulgui i no la que vulgui l'Estat. Serà molt bonic veure com es construirà.

Esperem que sí, que aquesta xarxa d'informació de temes tan propers a la comunitat educativa es pugui anar estenent. Del sistema educatiu finès n'has comentat els punts forts, però també en deu tenir de febles. Quins són i què s'està fent per compensar-los?

El mateix dia que van sortir els resultats de l'informe PISA, com que en aquesta edició van baixar una mica, al web del Ministeri d'Educació van penjar una informació en totes les llengües, entre les quals el castellà. La ministra deia que s'havien detectat dos problemes que havien fet baixar una mica els resultats. El primer, a causa d'una certa desvaloració d'alguns alumnes i de les famílies cap a l'escola; per tant, es tracta de veure com tornar a prestigiar el fet d'educar. El segon, causat per la crisi econòmica, que ha augmentat la disparitat entre rics i pobres i, per tant, el problema és d'equitat. Doncs bé, la ministra el primer que va dir és que aquests focus d'equitat s'han de resoldre i estem parlant d'una senyora de dretes d'un partit conservador, fet que aquí sorprèn.

Per tant, ells el que fan és analitzar la situació; en aquest cas, han vist que a causa de la crisi hi ha hagut un augment de la inequitat i decideixen resoldre-ho. Per què passa tot això? Doncs bé, primer, perquè amb els mitjans de comunicació que existeixen i dels quals hem parlat abans, hi ha molts nens i nenes que ja no van a la biblioteca com abans, estan més tancats a casa amb els ordinadors, la cultura americana està influint molt a la cultura finlandesa i això comença a calar en la joventut. A més, els valors dels pares comencen a xocar amb aquesta societat nordamericana, que no és la seva però que està entrant i empenyent amb força.

D'altra banda, tenen problemes previs a aquests; de tant en tant, a Finlàndia hi ha situacions molt dramàtiques en què un alumne entra $\mathrm{a}$ una escola i mata algú: el director, un alumne... N'heu vist notícies. Cada quatre o cinc anys es dóna algun cas d'aquestes característiques i ha passat unes quantes vegades. Ells estan molt preocupats, molt; penseu que l'última vegada que van entrar a una escola van matar la directora, vuit o nou professors i uns quants alumnes i un dels que ho van fer era fill d'una mestra.

Com és possible això? A Finlàndia és poc conegut, però hi ha moltes armes. En tenen moltes perquè és un país amb molta natura i és freqüent que la gent tingui permisos de caça. Tothom va a caçar amb el pare, l'avi, i a casa hi ha armes. Això fa que tinguin accés a escopetes, rifles i altres armes de foc fàcils d'aconseguir. Gairebé totes les famílies en tenen alguna a casa i ensenyen als fills a fer-les servir i hi tenen accés perquè les tenen a casa. 
Un altre aspecte que no funciona és el fet que hi hagi tantes situacions familiars trencades. Malgrat que ells han preservat la via educativa, no passa el mateix amb l'emocional, hi ha molta gent que se sent malament, he vist molta gent sola, molts homes sols, molts homes destrossats i molts fills que no connecten amb els pares. Tot això passa factura.

D'altra banda, els finlandesos tenen una gran competència lectora, però jo crec que la competència oral comunicativa no està ben desenvolupa$\mathrm{da}$, tenen dificultats per expressar els sentiments i les emocions, i és un fet que culturalment no s'afavoreix, tampoc a les escoles. Aquesta va ser una de les indicacions que jo els vaig fer. Quan vaig fer les propostes de la meva tesi, vaig fer-ne 107 per al govern espanyol i una vintena per al govern finlandès, que anaven bàsicament encaminades a la millora de problemes emocionals que tenen i que són fàcilment observables quan hi vas.

Per què moltes dones van dient que s'han separat un altre cop? Si porten quatre separacions, alguna cosa hi ha. Per posar un exemple, el cas d'una professora universitària molt agradable que vaig entrevistar el primer any, era al voltant de 1991. Allà hi ha el costum que quan et cases adquireixes el cognom del marit. Doncs bé, al cap d'un any hi vaig tornar i en preguntar per ella a secretaria no la trobava, s'havia tornat a casar i tenia un altre cognom. Finalment, la vaig trobar $\mathrm{i}$ la vaig anar a veure. Això us ho explico perquè és una mica surrealista, perquè al cap de pocs anys de casar-se ja s'havia separat per tercera vegada i a la quarta estada ja no la vaig anar a veure, perquè vaig pensar: "a veure si el cinquè seré jo."

Personalment, és un fet que em sorprèn, quan anava a les escoles i parlant amb les professores em comentaven que era bastant comú que les dones se separessin, fins i tot tres i quatre vegades; em resultava difícil d'entendre. Reflexiones i et planteges que hi ha alguna cosa que no va a l'hora, veus que els homes estan molt malament emocionalment. Per què? Doncs perquè tot això té les seves conseqüències.

És un dels països on hi ha més denúncies de violència de gènere del món perquè la dona té molt poder. A Finlàndia la llei empara molt la dona i els homes estan tan desesperats que les re- accions que tenen són molt primàries. Això ens està dient que hi ha alguna cosa que s'hauria de solucionar. La pobresa a Finlàndia és masculina i és freqüent veure homes enfonsats, fet que em va generar malestar. Trobo molt bé que la dona estigui protegida, però la sensació que el que estava desprotegit era l'home i que per això hi havia tants suïcidis d'homes va ser molt impactant. Per tant, això s'hauria de revisar i penso que un dels aspectes que hi pot influir és que la dimensió emocional no es té en compte ni a les famílies ni a l'escola.

Nosaltres tenim una manera de fer en què la gent se sol expressar emocionalment, hi ha una vida cultural llatina, amb la qual ells se sorprenen molt. Per a ells això és impensable, és molt més fàcil que nosaltres puguem incorporar aquí algunes coses del seu sistema educatiu que no pas que ells canviiin aquest substrat cultural.

No és or tot el que lluu, totes les societats tenen punts forts i febles i està bé conèixer-los. Nosaltres tenim coses que estan molt bé i les hem de saber i de valorar. Tots els estrangers que conec estan gratament sorpresos de com es viu de bé aquí. Tenia uns alumnes aquí a l'escola fa anys de pare japonès i un dia ens va dir que l'empresa els havia obligat a signar el contracte per tres anys perquè la majoria dels japonesos que vénen a Espanya no volen tornar de tan bé que se senten aquí. Això ens hauria de fer pensar. La nostra societat té coses molt bones que a vegades no som capaços de veure.

L'Organització per la Cooperació i el Desenvolupament Econòmic (OCDE) acaba de publicar els resultats del cèlebre informe PISA de l'últim trienni. Destaquen en els primers llocs els estudiants dels països asiàtics, Finlàndia baixa a la $12 a$ posició $i$ Catalunya es manté igual. La consellera d'Ensenyament, Irene Rigau, atribueix aquest estancament a la incorporació de l'alumnat d'origen estranger. Quina és la seva valoració dels resultats en general i de Catalunya en particular?

Efectivament, aquests dies hem vist a l'informe PISA que hi ha països que ocupen les primeres posicions, com Singapur, Corea del Sud, Hong Kong, també Taipei... Els països del sud-est asi- 
àtic han obtingut millors resultats que els països europeus.

Una explicació pot ser la manera com se selecciona la mostra, amb un sorteig. Hi ha un mostreig estadístic molt ben fet que és totalment independent del Departament d'Ensenyament, al qual tan sols li comuniquen els col-legis d'aquí i d'allà que formaran part de la mostra; si hi ha més o menys immigrants d'un centre o un altre es té en compte, en certa manera. El que va passar és que van tocar a l'atzar algunes escoles amb percentatges molt alts d'alumnat estranger, fins i tot a alguns centres els sabia greu perquè pensaven que les proves no sortirien bé. Amb això no vull dir que aquesta sigui l'única explicació. Posem l'exemple de la Comunitat de Madrid: ha tret bons resultats, fins i tot millors que Catalunya, $\mathrm{i}$ també té un percentatge d'immigrants molt elevat. Per tant, no solament ha de ser això, hi ha altres aspectes que hi influeixen i hi hem destar oberts. El tema és preguntar-se si seria interessant anar a Madrid per veure què passa i fer una anàlisi comparativa i poder detectar les possibles causes.

Laltre dia vaig escoltar uns arguments molt interessants sobre això. El Sr. Pablo Zoido, l'expert espanyol de l'OCDE, va dir que havien pogut comprovar que tots els alumnes immigrants d'Europa tenien cent punts més de mitjana que els nois i noies del país de procedència. És a dir, immigrar a qualsevol país de l'OCDE representa per a aquelles criatures més d'un any i mig d'avantatge sobre els que es van quedar allà. Això vol dir que, malgrat totes les dificultats que veiem, aquestes criatures han fet una enorme millora respecte als països dorigen, fet que moltes vegades no som capaços de veure. I és que en aquests països s'està fent una gran labor d'acollida i una millora qualitativa molt gran per a aquestes criatures.

Personalment, veig l'informe d'una altra manera. Si els resultats del nostre país són iguals que els de fa deu anys però tenim més alumnes de origen estranger, vol dir que ho estem fent més bé del que sembla perquè, tot i les dificultats, estem integrant aquest alumnat de tal manera que les mitjanes a l'informe final surten més o menys igual. És a dir, que fins i tot tenint aquestes difi- cultats, el país està avançant i ho està fent integrant aquests escolars d'una manera digna. Així que felicitats a totes les escoles i a totes les comunitats que estan fent aquesta feina. El nostre país hauria d'estar orgullós del que hem pogut fer en aquest sentit. Amb la gran crisi econòmica i social que estem vivint, aquestes persones d'origen estranger se senten còmodes, se senten bé aquí a les nostres escoles i la gent no vol marxar d'aquí. No volen marxar no pel tema econòmic, sinó perquè amb la xarxa humana i emocional que hi ha aquí s'hi senten bé, i això no surt a PISA, malgrat que és molt important.

Sense treure importància als resultats dels informes PISA, no creus que a més de valorar la competències cognitives com la lectora, la matemàtica i la científica també s'haurien de valorar altres competències de caire personal i social?

Hi ha moltes coses de l'informe PISA que potser no se saben; de fet, s'han publicat els resultats de les quatre coses més bàsiques, però després PISA té penjats cinc volums d'unes cinc-centes pàgines cadascun, que quan el llegeixes et sorprèn. Per exemple, la informació que surt sobre el tema de l'atenció a la diversitat, que s'ha de llegir amb tranquil.litat. Jo encara m'ho he de llegir. Laltre dia vaig mirar el primer volum, i em vaig dir: "Xavier, són 500 fulls, aquest període de Nadal m’ho llegiré a poc a poc." És bonic veure que a l'informe PISA hi ha molts detalls que es tenen en compte, perquè és la primera vegada que tenim dades mundials de molts paràmetres $i$, a més, està fet d'una manera molt rigorosa.

Normalment, la informació que es mostra i que circula en els mitjans de comunicació és incompleta, es pot limitar al llistat de països situats en les primeres posicions i si no hi ets, es veu com un fracàs. Doncs, escolta'm, jo no ho crec. Penso que Catalunya ha fet un gran esforç i no hem de focalitzar l'estancament dels resultats en l'alumnat immigrant. Hem de dir-nos que fins i tot amb aquests condicionants desfavorables, crisi inclosa, hem estat capaços de mantenir-nos estables. Així que cal felicitar l'escola i la societat catalanes, que estan integrant l'enorme onada de persones immigrants que han anat venint, d'una manera civilitzada i acollidora, i han fet que els 
resultats, malgrat tot, es mantinguin, perquè el que seria normal és que, entre la crisi i les retallades, haguessin baixat bastant i no ha estat així.

És cert, però tendim a mirar el que manca en lloc de veure i valorar el que tenim; realment les teves reflexions hi aporten una nova mirada.

Si ho mirem fredament és així, perquè és normal que amb la crisi que hi ha, amb els problemes d'equitat que hi ha, amb la quantitat de nens i nenes que no mengen, amb tota la gent nouvinguda, fins i tot amb tot això, aquests nens han fet una millora, se'ls ha inclòs en tot. Jo crec que l'escola ha fet i està fent una tasca preciosa d'integració i algun dia ho reconeixeran.

Llegint l'informe PISA es pot pensar que per assolir molt bons resultats la competitivitat entre l'alumnat ha de ser molt alta. Competir és la millor manera d'aconseguir millors resultats? Si posem l'èmfasi en la competència, com es podrà aprendre a cooperar?

Estic d'acord en això que dius. Aquests països que han tret tan bons resultats a l'informe PISA tots es basen en la competitivitat. Penso que aquest model, del "jo sóc més que tu", portarà a la confrontació. Hi ha un grau tan alt de competitivitat entre ells, els japonesos són més que els coreans, els coreans més que els coreans del nord, els del sud més que els xinesos, els xinesos més que els de Taiwan, els de Taiwan més que els altres, que inevitablement està fent que els individus pensin que han de ser millor que els altres encara que per ser-ho hagin d'esclafar el del costat, i aquesta dinàmica no pot acabar bé. Formarà persones amb una agressivitat i competitivitat desmesurades. Quan aquestes generacions arribin al poder i hagin d'executar accions, comportarà confrontacions, perquè és la mentalitat en què s'han anat formant i és incompatible amb el concepte de cooperació.

Veus com això no pot portar res bo? És impossible perquè ho pagaran ells mateixos com a éssers humans. No tindran infància ni adolescència i, a més, els hipotequen el futur, estaran tota la vida lluitant per intentar ser millors que l'altre i no ho aconseguiran mai, perquè mai no estaran satisfets. A la Xina aquest sentiment s'agreuja amb la política del fill únic, ja que totes les esperances de la família es canalitzen a fer que sigui el millor. La supervivència de la família en dependrà, fins i tot els avis. Imagina't quina vida tindrà, com viurà aquell noi o aquella noia amb una motxilla tan carregada a l'esquena.

Als anys noranta va venir d'Hiroshima el fill d'uns amics a estudiar aquí i va estar uns mesos a casa nostra, al carrer Comtal, mentre no trobava un lloc. Ens va dir: "Fins que no he arribat aquí, no m'he sentit lliure, per la pressió que tenia al damunt. Jo no penso treballar per res del món.”

Això no ho valorem perquè nosaltres no ho vivim, però aquesta manca de llibertat, la creació d'individus sotmesos a l'estat, especialment en estats més totalitaris, deu ser terrible, com pot ser el cas de la Xina. En el fons el que volen aquests governs és crear individus poc lliures i, inevitablement, poc creatius, perquè la creativitat va molt lligada a la llibertat. Podran copiar de tothom el que vulguin, però no podran innovar. Acabaran tenint problemes perquè la gent no podrà crear una estructura diferent si mentalment no té el permís de fer-ho. Sense el permís mental, la societat no pot traspassar els límits i anar més enllà. Si resulta que surts del marc que t'han establert, ets un marginat. Així, doncs, les persones solen respectar els límits, fins i tot la imposició del nombre de fills.

Però això no es reflecteix en els resultats: els del Japó, a l'informe PISA, surten maquillats; després t'adones que molts estudiants japonesos, quan han acabat els estudis previs a la universitat $i$ han aconseguit entrar a Tokio, es queden un any sense fer res, no poden més i se'n van de viatge. Tenen un problema d'identitat molt gran, de saber cap a on van a causa de la pressió a què han estat sotmesos. I això no és res, perquè les universitats japoneses són de primera, segona $\mathrm{i}$ tercera categoria, i depèn d'on hagis pogut entrar tindràs un títol i un sou de primera, segona o tercera, i això inevitablement, condicionarà la teva vida i la dels teus. Al Japó hi ha un milió de nois entre setze i divuit anys tancats a casa, malalts d'excessiva pressió. Aquests éssers humans han estat destruits mentalment i existencialment. Aquestes criatures no tenen vida. Aquest és el preu que volem pagar? Jo no ho vull, això, per 


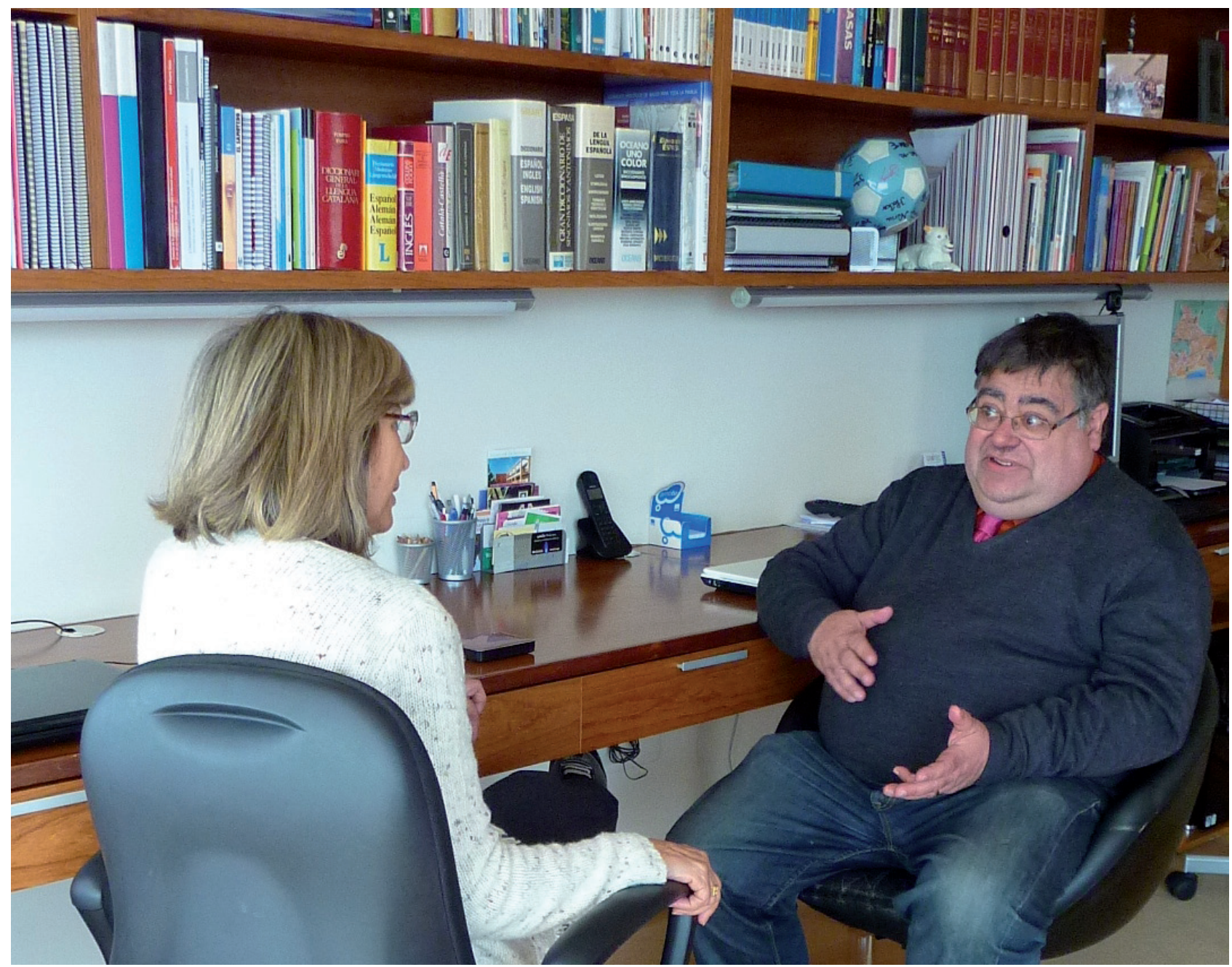

als meus ni tampoc té res a veure amb les meves conviccions ni espirituals ni humanes.

El que té de bonic el model europeu és que, després de donar-nos bufetades durant segles, la gent es va adonar que no hi ha més solució que cooperar, a poc a poc i pactant, ja que la vida de l'altre és tan important com la meva. I això que França i Alemanya van entendre tan bé i que va ser l'embrió del que ara tenim és per on hem d'anar, perquè el plantejament de la competitivitat i la confrontació és el que va desencadenar la Primera Guerra Mundial. Per tant, jo crec que és un gravíssim error i és molt perillós que la resta del món copiï aquest model, perquè implicarà un escenari de confrontació interna, tots aquests nens que estan traient aquest rendiment ho estan fent per ser millor que tots els seus companys, però molt millors, per poder estar per sobre dels altres amb l'objectiu de poder anar a la universitat. Els finlandesos no van amb aquesta idea, sinó que posen l'accent en el desenvolupament de la competència personal i del treball cooperatiu.

El que volen a Finlàndia és que tots tinguin la mateixa igualtat d'oportunitats, que a la universitat hi vagin tots els que vulguin. Aquest sí que és un escenari que lliga amb totes les meves creences. Si els finlandesos han tingut tan bons resultats és perquè la seva finalitat és formar els ciutadans i la manera com els formen no té res a veure amb els països que dèiem que havien encapçalat la llista. No tot és competitivitat, aquesta concepció de l'alumne com si fos una màquina de produir o un esclau, sinó que és un ésser humà amb tota la dignitat i això és el que m’agrada del seu model. Encara que actualment els seus resultats en l'informe PISA no siguin tan alts com els dels japonesos o els coreans, que s'han posicionat com a capdavanters, ja signaria per tenir la seva concepció d’alumne i els seus resultats. 
Fins aquí he fet referència a l'informe PISA, però cal dir que també hi ha una organització formada per mestres que valora altres aspectes: l'Associació Internacional per a l'Avaluació del Rendiment Educatiu (IEA). És una cooperativa internacional independent de les institucions nacionals i de les agències governamentals de recerca. Realitza estudis comparatius a gran escala de l'èxit educatiu i d'altres aspectes de l'àmbit educatiu. La IEA va ser la primera del món a fer les proves de competència lectora. Aquesta organització i l'OCDE, que és governamental, són molt diferents i el seu enfocament no té res a veure, fins i tot hi ha molta tensió entre elles. Els pioners a fer proves de competència van ser els de la IEA i els de l'OCDE les van imitar, tot i que ho van fer en una altra direcció.

Des de la IEA es van fer proves de competència lectora, matemàtica, científica i d'actituds cíviques. La iniciativa va sorgir perquè el que els interessava inicialment era veure com poder ajudar-se entre els mestres; per tant, les proves es fan en dos moments de lescolarització, a 9 i a 14 anys. Ho fan perquè el que volen és enviar senyals als mestres per veure què passa en el procés; en canvi, l'OCDE fa les proves únicament a l'edat de 15 anys, perquè als governs dels diferents països el que els interessa és la visió dels resultats finals. Per tant, l'objectiu d'uns i altres és molt diferent.

\section{Els resultats de les proves de l'Associació Interna- cional per a l'Avaluació del Rendiment Educatiu es publiquen?}

Sí, si tu busques a la IEA les proves d'actitud cíviques les trobaràs. L'última vegada que les van fer els resultats dels alumnes finlandesos també estaven dalt de tot. El que és interessant del seu sistema educatiu és que al final demostren que, amb menys hores d'estada a l'escola i tenint algunes tasques que incideixen en les actituds, l'alumnat surt molt competent en les tres àrees curriculars i, a més, amb unes actituds cíviques i ciutadanes molt integrades. Això és molt important perquè demostra que estant formant "persones integrals reals", és a dir, no són màquines de treure bon rendiment. En canvi, en altres països que encapçalen la llista PISA, com els del sud-est asiàtic, s'haurien d'analitzar per donar-nos una idea de com estan en relació amb les actituds cíviques; de fet, n'hi ha que no han volgut participar en aquestes proves. Per precisar-ho més, cal dir que alguns països no han volgut i a d'altres no els han deixat participar. Per què? Doncs perquè alguns d'aquests governs que han fet tanta xerinola són molt totalitaris i els governants no volen perdre el control de l'avaluació deixant que siguin els mateixos mestres qui avaluïn, $i$ aquests aspectes no es mesuren. Pel que va dir Pablo Zoido, em penso que hi ha intencions de mirar d'incloure els aspectes actitudinals de consciència cívica, tot i que aquests són més difícils de pactar entre els alemanys, els francesos, els anglesos, i difícilment es posaran d'acord. En canvi, en competència matemàtica, científica i lectora és possible. Pot ser que en música es pugui fer, però el que implica els aspectes emocionals i actitudinals, tal com s'ha enfocat, serà molt difícil de tractar. De moment s'ha començat per aquestes competències, però n'hi ha més, ja saps que són 8 les competències bàsiques; de fet, n'hi ha 9 , una de més amagada, que és la competència espiritual: d'aquesta ni tan sols se'n parla i crec que algun dia se’n haurà de parlar.

Fa de bon escoltar que una organització internacional formada per professionals de l'educació s'hagi preocupat d'avaluar aspectes humanistics de caire personal, actitudinal i social. Quina és la clau de l’èxit si ens referim als mètodes que utilitzen els professors finesos i quin valor donen a les metodologies que parteixen de situacions vivencials $i$ pràctiques properes a l'experiència de l'alumnat?

Les classes no són tan llargues com aquí, són de 45 minuts. Normalment s'inicien amb una activitat d'alta motivació per captar l'atenció de l'alumnat; continuen amb una altra de 15 minuts més, que pot ser l'explicació del professor o una proposta de treball en grup - de fet, es treballa molt en grup-, i es conclou amb una activitat d'autoavaluació del procés on la comunitat parla del tema. Els exàmens són escassos i es té molt en compte l'autoavaluació, però per a això el primer que s'ha d'avaluar és el professor, que ha de reflexionar sobre el que està fent. 
Les activitats inicials intenten combinar-les amb aspectes socials relacionats amb l'art, amb alguna cosa estètica, perquè tenen la convicció que l'aprenentatge ha d'entrar per l'emoció i per la bellesa i, si no entra així, és més difícil que arribi a les criatures. Això no té res a veure amb el que hem parlat de Corea o la Xina, no té res a veure amb el "copejament insistent", sinó amb la idea de considerar que "menys és més".

Menys quantitat, més aprofundiment i associat a què? Doncs a la bellesa, a l'emoció, a la vida. Això ho fan molt bé els mestres de Finlàndia, els eduquen molt bé. Són capaços de crear un estat emotiu potent a cada situació d'aprenentatge que plantegen, busquen com lligar-ho i, a més, donen una gran autonomia perquè els alumnes ho desenvolupin. Finalment, són ells mateixos els responsables del seu aprenentatge; per tant s'autoavaluen. Així, es formen uns alumnes molt responsables, molt motivats per a l'aprenentatge i són ells mateixos els que busquen les respostes.

L'aula és com un laboratori de recerca en el qual tothom aprèn. Lalumnat és molt participatiu i pregunta molt; de fet, quan vas allà et sorprens perquè els nens i nenes bombardegen de preguntes el mestre. Consideren que l'aprenentatge és una cosa seriosa i això fa que el grau d'implicació sigui alt i amb una actitud de respecte cap als altres: "jo no puc estar molestant els companys", i a classe hi ha un ambient de treball tranquil. La família ho reforça, tenen un gran respecte a la figura del mestre i col-laboren conjuntament. Quan el mestre diu a la família que el seu nen o nena no calla, busquen solucions per canviar aquesta actitud. Aquí, a les nostres escoles, davant d’aquesta situació, moltes famílies responen que no se'l motiva prou o que no hi poden fer res, llavors el mestre té la sensació de no estar acompanyat. D'uns anys ençà, aquests aspectes han canviat, el respecte que es tenia pel mestre, en molts casos, ha minvat, fins i tot hi ha famílies que s'hi enfronten, li diuen que no ho fa bé, que passa del seu fill i el mestre es planteja què més vol que faci aquesta família.

També trobem famílies que no tenen els mateixos valors que l'escola. Hi ha estudiants que acaben abandonant el sistema educatiu a tot
l'Estat espanyol, no tan sols a Catalunya, perquè consideren que no cal estudiar per guanyar-se la vida. De fet, aquí, al Col-legi Claret, he escoltat uns quants pares dient-me que ells es guanyen molt bé la vida treballant a la construcció i sense tenir estudis. L'alumne, quan acaba els estudis de l'ESO, en aconsellar-li que faci el batxillerat, la seva resposta és que se n’anirà a treballar amb el seu pare a l'obra perquè guanyarà molts diners. Al cap d'un any, un d'aquests nois va tornar a veure'm amb la moto per dir-me que guanyava el doble que jo i ara, amb tot el que ha passat, s'ha quedat sense feina, sense estudis i segurament sense moto, i aquest és el drama. A vegades penso que aquest model de vida ha malmès molts joves. Es poden llegir molts articles de professors que animaven els seus alumnes a estudiar i que ells se n'anaven a fer portes perquè hi havia una fàbrica de fusta al poble i al món de la construcció es pagaven molts diners i ara la fábrica ha plegat i els nois estan al carrer. És trist, però real.

El treball interdisciplinari a l'aula es té en compte sistemàticament? I, en cas que sigui així, en quines matèries: en algunes de concretes, en totes?

Què entens per treball interdisciplinari?

Doncs una programació, un projecte de treball que parteix d'un context determinat i que requereix l'aplicació de coneixements de diverses àrees. Per exemple, un projecte sobre un tema concret, el mar, en què participen conjuntament les àrees de didàctica de l'expressió corporal, l'expressió plàstica, l'expressió musical i llengua.

Doncs sí, es treballa molt per projectes. Aquí està tot molt compartimentat i seqüenciat: això és de lletres, això és de ciències... Allà inclouen continguts d’àrees diferents, especialment a l'educació primària, on gairebé tot es treballa per projectes i l'aprenentatge és compartit. A educació infantil es prioritza l'experimentació en contextos d'experiència significatius per als infants. El currículum és molt obert: penseu que a Finlàndia en aquesta etapa no s'ensenya a llegir; com que no es té la pressió ni la sensació d'haver de córrer, es respecta el ritme dels nens i de les nenes. 


\section{Es pot dir que els treballs són més globals?}

Més globals i més artístics, alhora que es potencia el treball en equip, però sense la pressa i la pressió que tenim aquí. Laltre dia em va trucar un pare, que és metge, per dir-me que estan molt preocupats perquè el seu fill de set anys encara no llegeix bé i que no saben què s'està ensenyant a les escoles. Doncs mira, a Finlàndia no comencen aquest aprenentatge fins als set anys.

Lestudi aprofundit del sistema educatiu finlandès m'ha fet dubtar de moltes coses que pensava tenir clares. No estic segur que ens equivoquem, però alguna cosa hi ha quan no ens en sortim prou bé. Potser sí que tenim creences que ens estan limitant molt i potser són les que no ens deixen avançar. Crec que ens hauríem de replantejar algunes coses. Al llarg de la història s'ha demostrat que el progrés ha estat possible gràcies a desfer-se d'algunes conviccions que es tenien. Un exemple clar el trobem en l'època de Colom, quan es pensava que la Terra era plana. Doncs bé, quan es va veure que aquella creença no era certa, al cap de pocs anys es navegava pertot arreu i no havien canviat els vaixells, els que havien canviat eren els que estaven a dins, les creences de les persones.

Què hauria de canviar per aconseguir una educació excel-lent per a tots els infants de la nostra societat, que seran la Catalunya del futur?

Jo el que vull són persones; encara més, jo crec que si es pot fer alguna cosa diferent a Catalunya és lluitar per això. És per aquí per on hem de construir, vagi per on vagi el futur del país. Els catalans som una gent que busquem alhora l'equitat i la qualitat i que volem una societat cohesionada que tingui uns valors. Tenim el potencial per fer-ho i ho estem demostrant cada dia; en podríem donar molts exemples, perquè hi ha molta voluntat i molt bona gent. I tot això sense recursos, imagineu-vos si algun dia l'economia del país torna a créixer; pot trigar més o menys, però creixerà i es disposarà de més recursos. Però el més important serà pactar el perfil de persona que es vol formar i, si s'acorda, crec que al país tindrem millores, n'estic convençut.

Possiblement no tenim els mestres tan ben formats com a Finlàndia, però s'està treballant en aquesta línia. Actualment formo part d'una comissió interuniversitària de Catalunya per la qualitat en què m'han incorporat com a analista extern. El MIF és un projecte per millorar la formació dels mestres amb la participació de totes les universitats catalanes, tant públiques com privades. Per primera vegada hi ha una voluntat dels degans i responsables d'ensenyament de les universitats per buscar noves estratègies i implementar-les per tal de millorar la qualitat de la formació dels ensenyants.

El país està molt bé; tot i que hi ha coses que possiblement no es veuen, estan molt ben plantejades i amb molt bona intuïció. A Catalunya hi ha un ambient de pacte, tot i que no és unitari, arran de la llei d'educació que es va aprovar amb el conseller Maragall. Podem veure aquesta cultura del pacte amb la consellera Irene Rigau, que quan es va aprovar la llei estava a l'oposició i ara la manté; és la primera vegada que això passa i segur que serà positiu, és molt diferent del que hem vist des de l'Estat.

Actualment afrontem la setena gran reforma educativa de la democràcia amb un ampli rebuig social. Entre mestres i professors s'estén el desànim. Xavier, hi ha res que, malgrat la penosa absència d'un pacte educatiu, mestres i professors puguem fer per millorar els resultats?

Jo penso que sí, penso en la teoria de sistemes i qualsevol canvi en algun lloc del sistema provocarà canvis a mitjà i llarg termini. Per tant, nosaltres hem de continuar per una senzilla raó: perquè la realitat de la vida no la fan les lleis, sinó que la va teixint la societat amb el seu dia a dia. Al final, els que farem els suèters som nosaltres, som les persones que teixim i no el que diu el teixidor. Crec que la llei Wert ens permetrà fer algunes coses que ens ajudaran i altres que no ens prohibirà, i tot el que no estigui prohibit es pot fer. Ja veurem si s'aplicarà o no, però el que no estigui prohibit ho podrem fer. El que hem de tenir molt clar és el que volem fer i per què ho volem fer.

La nota d'accés a la universitat, per alta que sigui, és suficient per aspirar als estudis de mestre 
o cal valorar altres competències? Si és així, quines serien les que destacaries?

Al nostre país l'educació no està socialment considerada una prioritat, no es valora el fet de ser mestre i els estudiants d'un nivell educatiu més alt no se senten atrets per la professió. En canvi, a Finlàndia la gent té la prioritat de formar-se, formar-se per construir. Els mestres a la universitat tenen la millor formació de tot el món universitari, el pressupost més alt s'inverteix a fer mestres. Ells saben que la millor formació que poden tenir a la vida és la de ser mestre; no és ser enginyer o arquitecte, sinó mestre, i a qui atreu això? Doncs a tothom, perquè el que un vol és la millor formació i no tothom hi pot accedir. No és un tema de diners, perquè els mestres a Finlàndia cobren més o menys com nosaltres; és un tema de prestigi social i de prioritat d'una societat.

Com que això atreu una gran quantitat de població, poden escollir les persones amb millors qualitats. A més a més de demanar una nota d’accés molt alta, els fan proves i entrevistes per valorar les competències, així com si han participat en alguna activitat de voluntariat, sigui quina sigui: la Creu Roja, un casal d'avis... Seleccionen persones compromeses i amb sensibilitat humana.

En el fons, la resposta és quin model de mestre volem, tenir-ho clar i actuar-hi en conseqüència. Per això penso que els requisits que demanen els finesos, adaptats al nostre context, serien totalment vàlids per accedir a la formació de mestre.

Què s'hauria de fer per donar-hi aquest prestigi, perquè la professió de mestre fos una professió valorada i de referència a la societat?

En primer lloc, cal buscar la manera de prestigiar la nostra professió. Crec que hem de pensar algunes estratègies que facin que, en els nostres valors socials, una de les prioritats sigui l'educació, cosa que ara no és així. Malgrat que jo no sé com s'ha de fer, penso que això ho capgiraria tot.

D'altra banda, em plantejo què és a les meves mans. Doncs parlar bé dels mestres i prestigiar-los, que és el que intento fer. Transmetre als nostres companys que ser mestre és un honor $\mathrm{i}$ que ells s'ho creguin, perquè ara no s'ho creuen. Els mestres s'han de mirar al mirall i dir-se que és un honor ser mestre perquè treballem amb un tresor, que són els nens i les nenes. Per tant, ens hem de sentir honorats i orgullosos perquè les famílies ens entreguen les vides dels seus fills, que són el més important que tenen.

Alguns dels vostres lectors segur que hauran passat situacions dificilíssimes, però han de sentir-se molt orgullosos, perquè, malgrat tot, els nens i nenes estimen molt els seus mestres i de molts d'ells se'n recordaran tota la vida, no tan sols perquè els han ensenyat llengua o matemàtiques, sinó perquè s'han sentit estimats.

Hem de valorar-nos més, dir-ho i també exigir, en la mesura que sigui possible, als nostres governants que prestigiïn aquesta professió i que la contemplin com una prioritat. Això vol dir que en els pressupostos de l'Estat i de la Generalitat l'educació sigui una prioritat. Quan veus que als països que formen part de l'OCDE la mitjana destinada a educació és d'un 5\% del PIB i Espanya no ha passat mai del $4,5 \%$, penses: "què fem aquí? L’educació és una prioritat?”. Doncs demostrem-ho i destinem-hi els recursos necessaris.

La part econòmica és molt important, perquè per atendre la gran diversitat que hi ha a les escoles es necessiten els recursos per poder-ho fer. Sóc una persona favorable a la integració, però no podem fer-ho sense les condicions necessàries. Què passa? Per què el professorat està tan cremat? No pot ser que amb alumnat que necessiti atenció individualitzada redueixin a la meitat l'horari del professional que se'n cuida, perquè aquest nen o aquesta nena està atès la meitat del temps i això és inacceptable.

D'acord, no hi ha diners; doncs bé, cal veure de què es pot prescindir. Al cap i a la fi, és un tema de prioritats. Vaig presenciar una conversa que em va fer mal, hi havia representants del Ministeri d'Educació de Finlàndia i del govern espanyol i els senyors de Finlàndia, del partit conservador, deien: "Retallin de tot arreu menys en educació." Això ho deien perquè Espanya havia d'anar a buscar ajudes a Finlàndia i a altres països. Ells no entenen que nosaltres retallem en educació i no en altres partides i no ens volen deixar diners. Ens ajudarien si els dediquéssim a l'educació, però no per invertir-los en l'AVE, infraestructures, construcció o en altres coses. 
Els estudis de Magisteri a Finlàndia tenen una durada de cinc anys; la carrera s'estructura en un primer cicle de tres anys i un segon cicle de dos. Quin tipus de coneixements tenen més pes: els que corresponen a matèries disciplinàries o els continguts de didàctiques específiques de les diferents àrees?

Els continguts disciplinaris tenen molt pes, però també el tenen les didàctiques específiques de totes les àrees; fins i tot la recerca en didàctica és molt potent i ho completen amb el treball final de carrera. Més de la meitat de les tesines que es presenten són de didàctiques específiques.

Es fa molta recerca en didàctica, contínuament s'està millorant $\mathrm{i}$ tothom nestà aprenent, perquè les recerques es publiquen a la universitat $\mathrm{i}$ això fa que millori constantment la qualitat. Això afecta directament la promoció següent, perquè els treballs de recerca que es fan al país de com millorar la didàctica de les matemàtiques a tercer $o$ a cinquè, $o$ els d'un àmbit concret com pot ser la geometria, en tenir difusió a la xarxa es van incorporant $i$ tothom va aprenent $i$ construint sobre aquestes innovacions docents.
Aquesta recerca educativa que es fa a la universitat arriba a les escoles?

Sí, no tan sols hi arriba, sinó que les escoles estan molt connectades entre elles i alhora ho estan amb les universitats. D'altra banda, els mestres són els primers lectors del país, aquest tipus de revistes com Comunicació Educativa se les llegeix tothom i, a més, participen en projectes de recerca comuns entre escola i universitat. La idea és crear comunitats d'aprenentatge i per això és necessari que hi hagi una vinculació entre els centres de recerca de més nivell del país, que són les universitats, i les unitats d'aplicació, que són les escoles.

Això crea una sinergia amb una potència fortíssima de cooperació universitària. Es difonen a la xarxa els coneixements, i es genera equitat i qualitat a la vegada, amb la qual cosa s'acaba potenciant moltíssim la qualitat arreu del país. Per això hi ha tanta equitat vagis on vagis - al nord, al sud, al est o a l'oest - o sigui quina sigui l'escola on vagis observes la implicació activa de l'alumnat en el procés d'ensenyament-aprenentatge, les metodologies actives i vivencials que utilitzen,

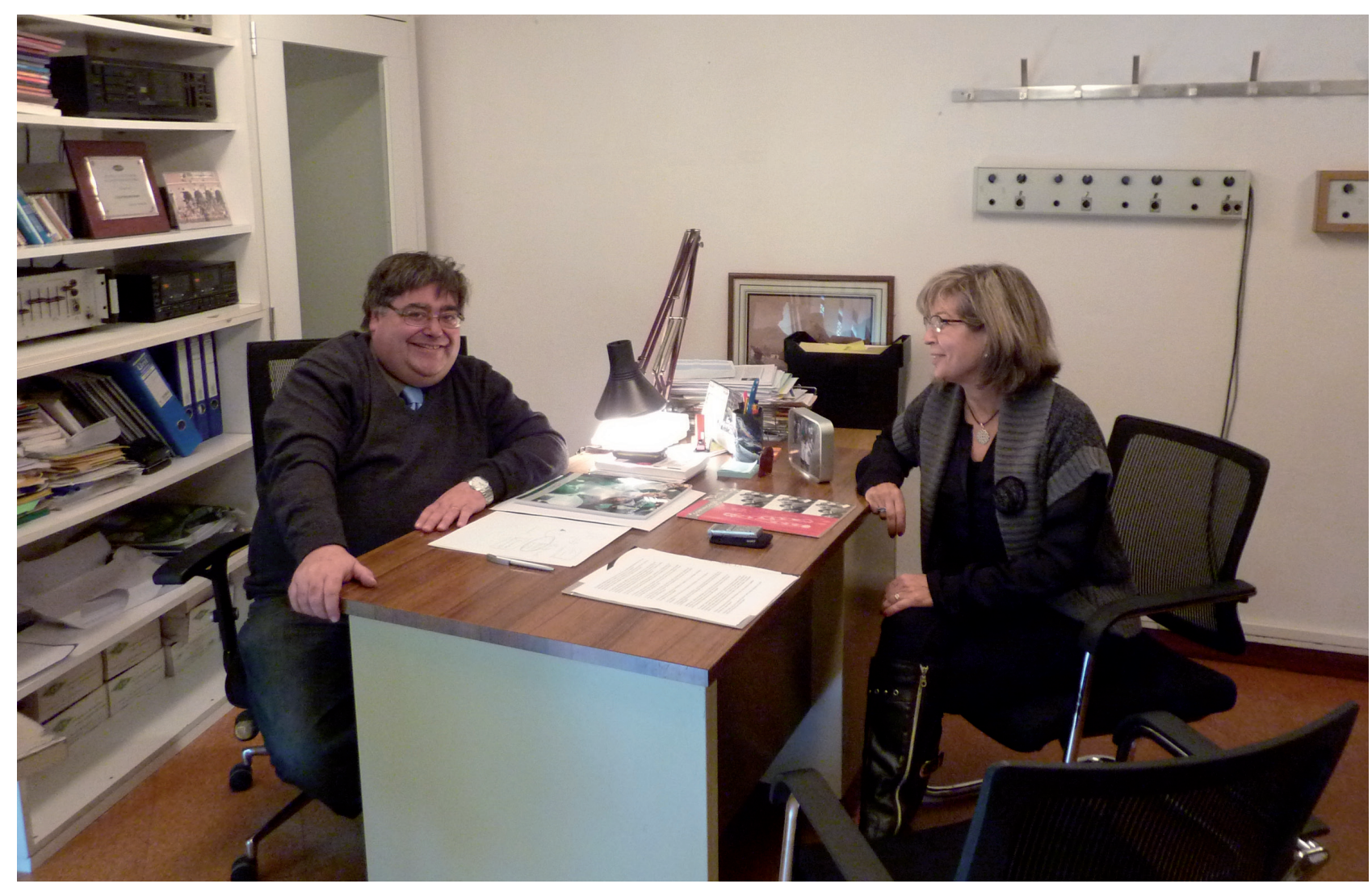


que fan que els nens i nenes participin en la presa de decisions, indaguin, resolguin problemes... Com pot ser que hi hagi tanta similitud si el mestre no s'ha format a la mateixa universitat i els plans d'estudis són diferents? Com he dit, la gent llegeix molt i sajuda molt. La paraula cooperació és en tots els projectes i també en les publicacions que fa el govern; l'important és cooperar i treballar en equip, fet que genera una potència $\mathrm{i}$ una cohesió de país molt gran.

Si entenem que formar mestres capaços de promoure el desenvolupament de persones a partir de la relació educativa vol dir formar professionals competents, capaços de saber aprendre a aprendre, de saber fer, ser i estar en relació amb els altres, quina seria la teva aposta a l'hora de definir el perfil de mestre competent?

Hauria de ser una persona integral, és a dir, una persona competent en totes les dimensions: física, intel-lectual, però també afectiva, moral i espiritual; si li manca algunes d'aquestes dimensions, malament rai. Una persona amb inquietuds, amb ganes de formar-se i d'aprendre contínuament, que sigui capaç d'estimar la seva societat, cada un dels nens i nenes, que expressi aquest afecte i que després lluiti per cadascun d'ells amb tot el coneixement que hagi adquirit per crear aquesta xarxa comunitària, per tirar endavant el país. Jo penso que amb aquests components es poden formar persones integrals; cal doncs, tenir mestres que també ho siguin.

Un dels degans de la Facultat d'Educació de la Universitat d'Hèlsinki, fa molts anys, em va dir una frase que després he repetit sempre que n'he tingut ocasió: "El mestre ha de ser el motlle en què jo vull fer les peces. Si necessito una peça d'una manera i no d'una altra, primer necessito un motlle ben fet i el necessito d'aquella manera", i aquesta és la idea. Busquem aquest tipus de persones, perquè el que jo busco finalment és això.
Espero que les persones que em llegeixin comparteixi això, i si no, no passa res, però jo penso que el futur està buscant aquest tipus de persones. Els mestres han de ser persones competents per formar persones i no competidors com ja he comentat abans.

Per acabar, quines recomanacions faries a l'administració per tal de millorar el sistema educatiu de casa nostra?

Cal que ajudi a prestigiar aquest professorat, perquè aquí es pot fer molt de mal. Diem que tenim professorat dolent i no és així; en general, tenim uns docents que han fet tot el que han pogut per tirar endavant el projecte que se'ls ha encomanat. Els diria que si volen millorar l'educació ho demostrin amb fets, que ens donin suport i que estiguin al costat del professorat. Per prestigiar aquesta professió cal que hi destinin els recursos necessaris, que no es digui una cosa i després se’n faci una altra, que si hi ha camins que per alguna raó es bloquegen els desmuntin i en construeixin de nous. Que realment facin de l'educació una prioritat nacional, perquè al final l'important per als ciutadans de Catalunya és com construïm aquests nois i noies.

Moltes gràcies, Xavier, gràcies per l'entrevista, però també per ser una gran persona i per la teva implicació a voler millorar l'educació del nostre país.

Per a mi ha estat un plaer. Jo aquí he tingut molt bons mestres i sóc el que sóc perquè he estat envoltat d'aquesta gent. En certa manera sóc com un claretià, perquè en el fons l'únic que he fet ha estat agafar les arrels que jo tenia aquí i anar una mica més enllà en un altre país al qual ells no han pogut anar i dir el que he vist, i a partir d'aquí collaborar d'alguna manera en el que pugui. 